\title{
Development of curd product technology with the addition of grape seed oil
}

\author{
Yuri Gerber ${ }^{1 *}$, Alexander Gavrilov ${ }^{1}$, Vladimir Omelchuk ${ }^{1}$ and Ekaterina Oshchepkova ${ }^{1}$ \\ ${ }^{1}$ Academy of Life and Environmental Sciences, V.I. Vernadsky Crimean Federal University, 1A, the \\ Republic of Scientific street, 295492, village of t. Agrarian, Simferopol, Crimea, Russia
}

\begin{abstract}
The article is dedicated to the study of the raw materials in the Republic of Crimea, as well as to the assortment of enriched dairy products and the development of an enriched curd product. The relevance and novelty of this technology lies in the fact that the oil obtained from grape seeds is used as the added component. It has therapeutic properties that have been repeatedly proven. The objectives of the work were to substantiate the production technology of the curd product with the addition of grape seed oil for therapeutic purposes and to develop the technology, which will allow to obtain a product with high nutritional properties, the physicomechanical structure required by the standard, as well as to minimize the loss of beneficial components that make up grape seed oil.
\end{abstract}

\section{Introduction}

After we have studied thoroughly raw materials found in the Republic of Crimea, as well as the assortment of enriched dairy products, we decided to develop an enriched curd product. Grape seed oil, which was selected as its component, has therapeutic and prophylactic properties that have been repeatedly proven [1-3]. It is also planned to develop a technology, the essence of which is to obtain a product with high nutritional properties, the physical and mechanical structure required by the standard, as well as to minimize the loss of useful components that make up grape seed oil.

Grape seed oil, which has a very rich composition, has been considered a valuable food, cosmetic and medicinal product since ancient times. Currently, its main producers are France, Spain, Italy and Argentina [4-6].

The greenish oil from grape seeds with a delicate aroma began to be obtained as long ago as the time of prosperity of the great ancient civilizations. This unique natural product attracts so much attention not because of its caloric content, but because of a high concentration of vitamins, polyunsaturated organic acids, minerals, and other active substances (Fig. 1).

\footnotetext{
${ }^{*}$ Corresponding author: gerber_1961@mail.ru
} 

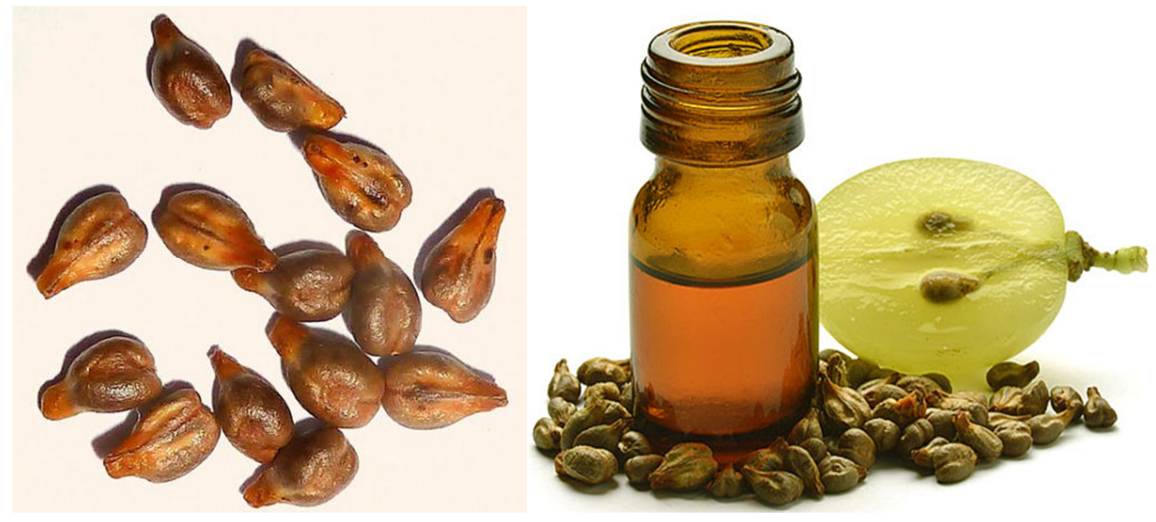

Fig. 1. Grape seed oil.

The composition includes vitamins $\mathrm{A}, \mathrm{E}$ and $\mathrm{C}$, as well as a wide range of $\mathrm{B}$ vitamins. At that, what makes grape oil peculiar among all other fats of plant origin is the highest concentration of vitamin E, which lowers cholesterol, strengthens and expands the walls of blood vessels, has anti-inflammatory effects, and also activates the body's natural defense [7-9]. Grape oil, in addition to a high concentration of the above mentioned vitamins, contains trace elements, chlorophyll, phytoncides, flavonoids, tannins, and natural enzymes. In addition, this oil is one of the leaders in unsaturated fatty acid content. It contains up to $70 \%$ omega- 6 and up to $25 \%$ omega- 9 acids, other fatty acids being present in this product in small quantities [10-12].

Omega acids are known not to be synthesized in the human body, but they are essential for the regulation of fat metabolism. Regular consumption of grape oil will help normalize lipid metabolism, reduce blood cholesterol owing to very low-density lipoproteins, which are responsible for the development of atherosclerosis [1-3,13]. Also, the use of this oil reduces the likelihood of thrombosis. The trace elements that make up the product support the normal functioning of the heart. Due to all these properties, grape oil is an excellent natural remedy for the prevention of atherosclerosis, cardiovascular diseases, varicose veins, has an anti-inflammatory effect and acts as a powerful antioxidant with anti-aging effect [14-16].

The purpose of the study is to substantiate the parameters of the technology of production of a curd product for therapeutic purposes with the addition of grape seed oil.

The objectives of the study.

1. Selection of ingredients to be added.

2. Selection of technological operations to be used.

3. Selection of temperature conditions for various steps of the technology process.

4. Identification of physicochemical and organoleptic characteristics of the resulting product.

5. The methodology of the experiment. The procedure, conditions, laboratory devices and equipment, methods.

\section{Materials and methods}

The following raw materials were used for the production of the curd product with the addition of grape seed oil:

- Skimmed milk (0.05\% fat content);

- Starter culture MOS-062D;

- Starter culture MOS-064E; 
- Calcium chloride;

- Milk-clotting enzyme;

- Grape seed oil.

All experiments were carried out at Teaching Technology Laboratory of Teaching Scientific and Technology Complex of Academy of Bioresources and Environmental Management of V.I. Vernadsky Crimean Federal University

Physicochemical and organoleptic parameters identified in the skimmed milk are presented below in tables 1 and 2 .

Table 1. Organoleptic Parameters of the Milk.

\begin{tabular}{|c|c|c|}
\hline No. & Parameter & Characteristic \\
\hline 1 & Taste and smell & Pure, without foreign flavors and odors \\
\hline 2 & Appearance and consistency & Homogenous liquid without sediment and flakes \\
\hline 3 & Color & White with a slightly bluish tint \\
\hline
\end{tabular}

Table 2. Physicochemical Parameters of the Milk.

\begin{tabular}{|c|c|c|}
\hline No. & Parameter & Value \\
\hline 1 & Fat content, $\%$ & 0.5 \\
\hline 2 & Protein content, $\%$ & 3.0 \\
\hline 3 & Acidity, ${ }^{\circ} \mathrm{T}$ & 17 \\
\hline 4 & Density, $\mathrm{kg} / \mathrm{m}^{3}$ & 1030.0 \\
\hline
\end{tabular}

Identification of physicochemical parameters was carried out on a Milk analyzer "Klever-22M" at $20^{\circ} \mathrm{C}$.

Moisture content in the cottage cheese was determined using a moisture analyzer Evlas2M.

Acidity was determined by acid-base titration in accordance with GOST 3624-92 "Milk and milk products. Titrimetric methods of acidity determination".

Basis for the selection of starter culture. At first, several types of starter culture were chosen for fermentation: MOS 062D, which contains a mixture of lactococci and thermophilic streptococcus, for the production of cottage cheese with a high moisture content and a more delicate texture; MOS 064E, which includes a mixture of lactococci and thermophilic streptococcus, for the production of cottage cheese with a normal moisture content and a crumblier texture. During the experiment, the starter culture MOS 062D was selected, since no separation of the product components was observed in the final product (the cottage cheese) obtained with it. The acidity of the product ranged from 160 to $180^{\circ} \mathrm{T}$ (table 3).

Table 3. Recipe for Determining the Amount of the Added Starter Culture.

\begin{tabular}{|c|c|c|c|c|}
\hline \multirow{2}{*}{ No. } & \multirow{2}{*}{ Added component } & \multicolumn{3}{|c|}{ Amount of added component } \\
\cline { 3 - 5 } & & Sample 1 & Sample 2 & Sample 3 \\
\hline 1 & Skimmed milk (mL) & 1000 & 1000 & 1000 \\
\hline 2 & Starter culture (g) & 0.40 & 0.50 & 0.60 \\
\hline 3 & Acidity, ${ }^{\circ} \mathrm{T}$ & 140 & 160 & 200 \\
\hline
\end{tabular}

In the first sample, $0.40 \mathrm{~g}$ of the starter culture was added. MOS 062D starter culture did not form enough curd in the process of fermentation; the acidity was $140^{\circ} \mathrm{T}$; the flavor was not sour enough; the curd was sloppy. The whey separation was slow. Thus, this amount of the starter culture was concluded not to be appropriate for further research.

In the second sample, the starter culture was more active in the process of fermentation; the curd was denser; the acidity was $160^{\circ} \mathrm{T}$; the flavor was sour enough. The whey separated better, but had an increased protein content. It was concluded that this amount of 
the starter culture was appropriate for further research under the condition that a milkclotting enzyme was to be used in order to minimize the loss of protein in whey.

In the third sample, the amount of the starter culture had no effect on consistency of cottage cheese, but affected its acidity, which amounted to $200^{\circ} \mathrm{T}$. The whey was separated not fast enough. Since the acidity of the resulted curd was too high and increased actively during storage, this amount of the starter culture was not appropriate for further research.

The basis for the amount of grape seed oil added to the curd product is presented in table 4.

Table 4. Recipe for Determining the Amount of Added Grape Seed Oil.

\begin{tabular}{|c|c|c|c|c|}
\hline \multirow{2}{*}{ No. } & \multirow{2}{*}{ Added component } & \multicolumn{3}{|c|}{ Amount of added component } \\
\cline { 3 - 5 } & & Sample 1 & Sample 2 & Sample 3 \\
\hline 1 & Skimmed milk (mL) & 1000 & 1000 & 1000 \\
\hline 2 & Starter culture (g) & 0.50 & 0.50 & 0.50 \\
\hline 3 & Grape seed oil $(\mathrm{mL})$ & 0.2 & 2 & 20 \\
\hline
\end{tabular}

In the first sample $(0.2 \mathrm{ml})$, the oil was not noticeable. The organoleptic characteristics of the product did not change, so this amount of oil was not enough. No separation of the systems was observed.

In the second sample, the oil content was not noticeable either. The organoleptic characteristics slightly changed, the flavor of the added oil was almost not felt. No separation of the systems was observed. Consistency was moderately homogeneous. During storage, separation began on day 5. This formula is appropriate for further research, as organoleptic indicators comply with GOST 31453-2013 "Cottage cheese. Specifications". Later on, it is necessary to develop technological instructions for manufacturing of this product.

In the third sample, the presence of oil was visually observed; grinding could not distribute it evenly throughout the volume of the product. The consistency was not homogenous; the separation was observed almost immediately after grinding. The oil taste was too clearly perceivable and intrusive. It was concluded that this amount of added oil was not appropriate for further research, since the organoleptic characteristics did not meet the requirements of GOST 31453-2013 "Cottage cheese. Specifications".

\section{Results}

Physicochemical and organoleptic characteristics of the curd product under study are presented below in tables 5 and 6 .

Table 5. Organoleptic Parameters of the Finished Product.

\begin{tabular}{|c|c|c|}
\hline No. & Parameter & Characteristic \\
\hline 1 & Taste and smell & $\begin{array}{c}\text { Pure, sour-milk, without foreign flavors and odors, with an aftertaste } \\
\text { characteristic of grape seed oil. }\end{array}$ \\
\hline 2 & $\begin{array}{c}\text { Appearance and } \\
\text { consistency }\end{array}$ & $\begin{array}{c}\text { Soft, smearing consistency with perceivable particles of milk protein. } \\
\text { Formation of small amount of whey was noticeable. }\end{array}$ \\
\hline 3 & Color & White homogenous \\
\hline
\end{tabular}

Table 6. Physicochemical Parameters of the Finished Product.

\begin{tabular}{|c|c|c|}
\hline No. & Parameter & Value \\
\hline 1 & Acidity, ${ }^{\circ} \mathrm{T}$ & 160 \\
\hline 2 & Moisture content, $\%$ & $80 \%$ \\
\hline 3 & Phosphatase or peroxidase & Not detected \\
\hline 4 & Temperature & $4 \pm 2$ \\
\hline
\end{tabular}


The acidity of the obtained samples of the curd product was determined during storage in the refrigerator at storage temperature $4-6^{\circ} \mathrm{C}$ for 7 days. During the study, it was noted that the acidity of this product increased more slowly than that of traditional cottage cheese with $9 \%$ fat content. The acidity of the finished product and traditional cottage cheese with $9 \%$ fat content during storage are presented in table 7.

Table 7. Acidity of the Product under Study during Storage at $\mathrm{t}=4-6{ }^{\circ} \mathrm{C}$.

\begin{tabular}{|c|c|c|c|}
\hline \multirow{2}{*}{ No. } & \multirow{2}{*}{ Day (x) } & \multicolumn{2}{|c|}{ Acidity, ${ }^{\circ} \mathbf{T}$} \\
\cline { 3 - 4 } & & $\begin{array}{c}\text { The curd product with the } \\
\text { addition of grape seed oil }\end{array}$ & $\begin{array}{c}\text { Traditional cottage cheese } \\
\text { with 9\% fat content }\end{array}$ \\
\hline 1 & 1 & 159 & 161 \\
\hline 2 & 2 & 163 & 166 \\
\hline 3 & 3 & 167 & 170 \\
\hline 4 & 4 & 170 & 176 \\
\hline 5 & 5 & 174 & 181 \\
\hline 6 & 6 & 178 & 192 \\
\hline 7 & 7 & 183 & 203 \\
\hline
\end{tabular}

The correlation was determined by the Pearson method (Fig. 2) [15].

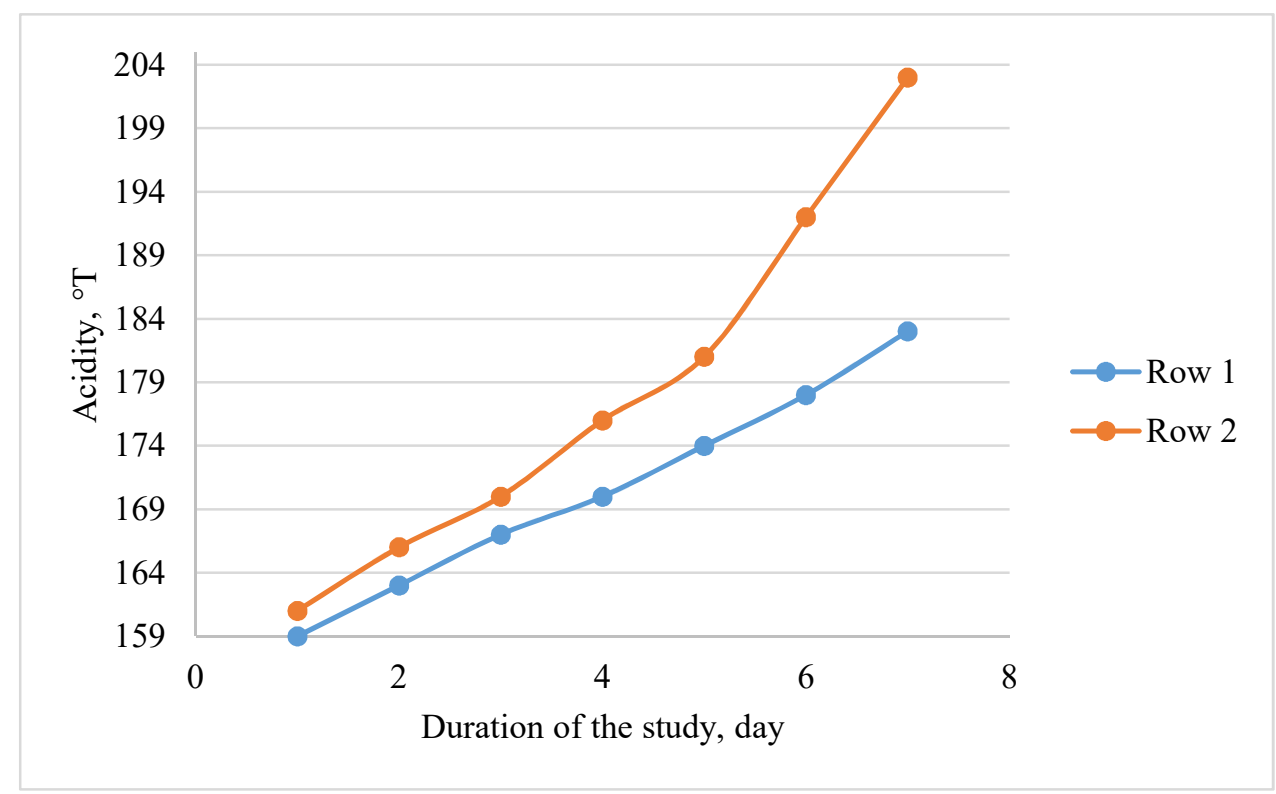

Fig. 2. The dependence of the acidity of the curd product with the addition of grape seed oil on storage time: row 1 - curd product with the addition of grape seed oil, row 2 - traditional cottage cheese with $9 \%$ fat content.

In this diagram, there is a correlation between the duration of storage and the acidity of the finished product.

The correlation coefficient between the shelf life and the acidity of the finished product is calculated by the formula:

$$
r_{x y}=\frac{\sum\left(x_{i}-y_{i}\right) \cdot\left(y_{i}-y\right)}{\sqrt{\sum\left(x_{i}-x\right)^{2} \cdot \sum\left(y_{i}-y\right)^{2}}}
$$

where $x$ is the storage time of the finished product, $y$ is acidity of the finished product, and $\underline{\mathrm{r}}_{x y}$ is a correlation coefficient. 


$$
r_{x y}=\frac{(28-4) \cdot(1194-170,6)}{24561,6}=1
$$

The correlation coefficient between the shelf life and the acidity of the finished product is equal to one, which means that there is a complete direct correlation between these factors [15].

The correlation coefficient between the days of storage and the acidity of cottage cheese with $9 \%$ fat content is calculated by the formula:

$$
r_{x y}=\frac{\sum\left(x_{i}-x\right) \cdot\left(y_{i}-y\right)}{\sqrt{\sum\left(x_{i}-x\right)^{2}} \cdot \sqrt{\sum\left(y_{i}-y\right)^{2}}}
$$

where $x$ is the day of storage of the finished product, $y$ is the acidity of the finished product, $\underline{\mathrm{r}}_{x y}$ is a correlation coefficient.

$$
r_{x y}=\frac{(28-4) \cdot(1294-178,4)}{25694,4}=1
$$

The correlation coefficient between the days of storage and the acidity of the finished product is equal to one, which means that there is a complete direct correlation between these factors.

Conclusion: when comparing the graph of the correlation between the same characteristics of different products, the acidity of the curd product with the addition of grape seed oil is observed to increase much more slowly than that of cottage cheese with $9 \%$ fat content with slight differences in the starting values $\left(2^{\circ} \mathrm{T}\right)$.

\section{Discussion and conclusion}

The parameters of separation of the curd product with the addition of grape seed oil are presented in table 8 .

Table 8. The Parameters of Separation of the Curd Product during Storage at $t=4-6 C^{0}$.

\begin{tabular}{|c|c|}
\hline Day & Degree of separation \\
\hline 1 & No separation of curd and oil is observed \\
\hline 2 & No separation of curd and oil is observed \\
\hline 3 & No separation of curd and oil is observed \\
\hline 4 & No separation of curd and oil is observed \\
\hline 5 & $\begin{array}{c}\text { There is slight separation of curd and oil though } \\
\text { it is almost unnoticeable }\end{array}$ \\
\hline 6 & $\begin{array}{c}\text { Separation of the two systems becomes more } \\
\text { noticeable }\end{array}$ \\
\hline 7 & $\begin{array}{c}\text { Separation of the two systems becomes more } \\
\text { noticeable }\end{array}$ \\
\hline
\end{tabular}

The degree of separation was estimated visually. Based on the data obtained, it can be concluded that the product remains stable for the first 4 days, and thereafter a gradual separation of the two systems is observed.

Based on the study, a formulation was obtained for the production of a curd product with the addition of grape seed oil.

Table 9. Formula of the Curd Product Enriched with Grape Seed Oil.

\begin{tabular}{|c|c|c|}
\hline No. & The ingredient & Amount of the ingredient \\
\hline 1 & Skimmed milk $(\mathrm{mL})$ & 1000 \\
\hline
\end{tabular}




\begin{tabular}{|c|c|c|}
\hline 2 & Starter culture $(\mathrm{g})$ & 0.50 \\
\hline 3 & Grape seed oil $(\mathrm{mL})$ & 2 \\
\hline 4 & Calcium chloride $(\mathrm{g})$ & 0.2 \\
\hline 5 & Milk-clotting enzyme $(\mathrm{mg})$ & 1 \\
\hline
\end{tabular}

Skimmed milk is pasteurized at a temperature of $78 \pm 2^{\circ} \mathrm{C}$ and cooled to a fermentation temperature of $28-30^{\circ} \mathrm{C}$. Then the starter culture, calcium chloride, milk-clotting enzyme (in the form of solutions) are added in accordance with the formula, thereafter fermentation takes place for 8 hours. After fermentation is completed the curd is put into curd bags, cooled and pressed to the desired moisture content. Then the curd is heated to $25-30^{\circ} \mathrm{C}$, and grape seed oil is added in accordance with the formula. It then is mixed thoroughly and sent to grinding. After grinding, the curd product is packaged and sent for cooling.

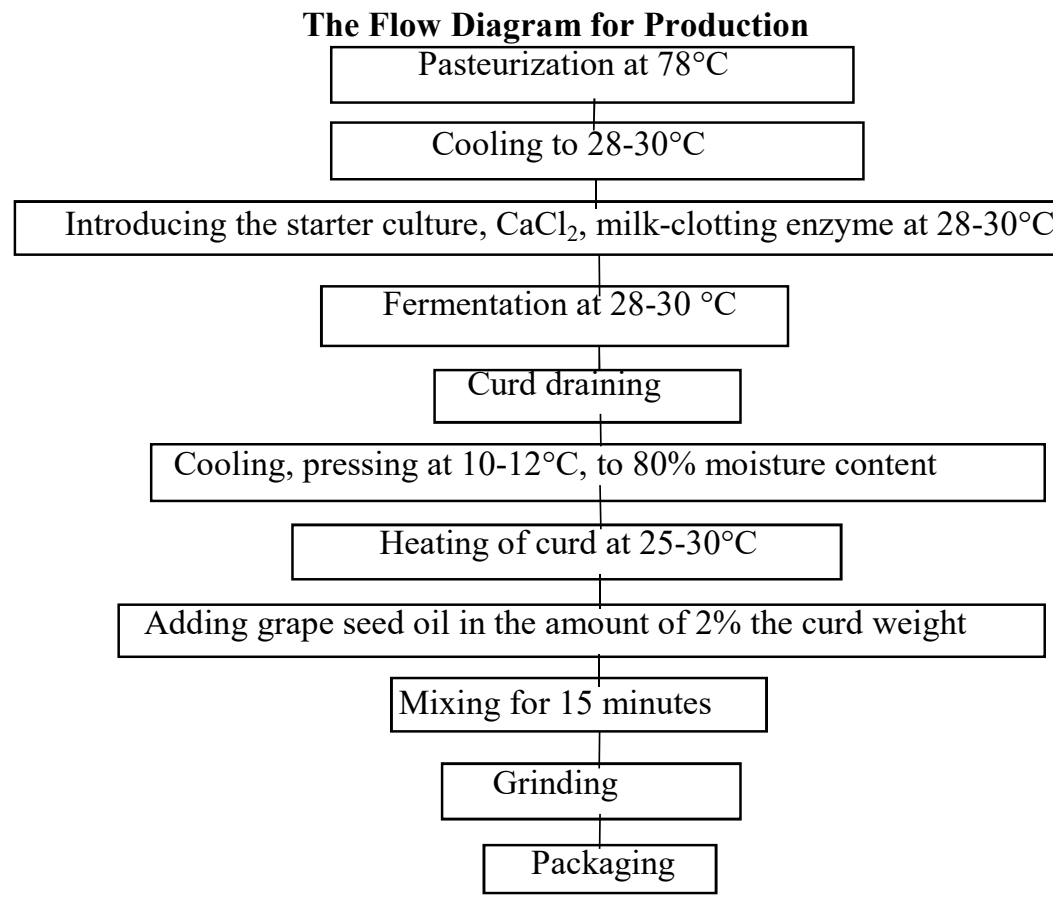

Fig. 3. Flow Diagram for Production.

\section{Conclusions}

We have analyzed normative and technical documentation and methods for the production of cottage cheese and curd products.

The research methods have been studied and selected. The physicochemical parameters of skimmed milk which served as the raw material for the production of skimmed cottage cheese were obtained.

In the course of the study, the parameters of technology for the production of the curd product with the addition of grape seed oil were substantiated. During the experiment, we also determined the range and the amount of the ingredients to be included, namely, the starter culture is introduced in the amount of $0.50 \mathrm{~g}$ per $1000 \mathrm{~mL}$ of milk, grape seed oil is added in the amount of $2 \mathrm{~mL}$ per $100 \mathrm{~g}$ of cottage cheese, calcium chloride is introduced in the amount of $0.2 \mathrm{~g}$ per $1000 \mathrm{~mL}$ of milk, and the milk-clotting enzyme is introduced in the 
amount of $1 \mathrm{mg}$ per $1000 \mathrm{~mL}$ of milk. Based on the data obtained, a formulation was developed.

We have created a process flow diagram, which includes pasteurization at temperature $78 \pm 2^{\circ} \mathrm{C}$, cooling to a fermentation temperature of $28-30^{\circ} \mathrm{C}$, the inoculation of the starter culture, fermentation for 8 hours, the curd draining in curd bags and pressing to the desired moisture content, heating the curd at $25-30^{\circ} \mathrm{C}$ and then adding grape seed oil, mixing, grinding, cooling. Temperature conditions were selected for various steps of the technology process.

The organoleptic and physicochemical parameters of the finished product were determined. An experiment to observe an increase in acidity during storage of the obtained product was carried out and a comparative analysis was conducted to compare the received parameters for the finished product with those for cottage cheese with $9 \%$ fat content. The article contains graphs of the correlation dependence of the acidity of the finished product and cottage cheese with $9 \%$ fat content on storage time under identical conditions at a temperature of $4-6^{\circ} \mathrm{C}$.

From the above, we can conclude that grape seed oil has a positive effect on the dynamics of changes in the acidity of cottage cheese during storage, in addition to the useful qualities of the oil, which are mentioned at the beginning of the article.

\section{References}

1. Yu.B. Gerber, A.V. Gavrilov, N.S. Kiyan, Bulletin of Agricultural Science of Tauris 8(171), 55-62 (2016)

2. Yu.B. Gerber, A.V. Gavrilov, Food Engineering and Technology 3 (2019)

3. O.V. Kozlova, T.Ch. Tultabaeva, Proceedings of the International Symposium (FSBEI HE Kemerovo State University, Kemerovo, 2018)

4. O.V. Krieger, XuWei, Proceedings of the International Symposium (FSBEI HE Kemerovo State University, Kemerovo, 2018)

5. O.V. Krieger, S.Yu. Noskova, Food Engineering and Technology 4, 30-38 (2018)

6. V.I. Dorovskikh, D.V. Dorovskikh, S. Allami, Science in central RUSSIA Tambov 5(23), 62-69 (2016)

7. L.A. Zabodalova, M.S. Solovieva, Scientific journal NRU ITMO. Series "Processes and Food Production Equipment" (2014)

8. O.N. Musina, M.P. Schetinin, Food industry (2017)

9. L.A. Bobrakova, A.V. Mamaev, Bulletin of agricultural science (2013)

10. O.V. Penzina, O.V. Pasko, Food industry (2013)

11. L.G. Germanskaya, O.V. Pasko, O.V. Penzina, Agrarian Bulletin of the Urals (2014)

12. D.L. Klabukova, S.E. Strogov, V.V. Turkin, N.G. Mashentseva, Food industry (2013)

13. L.G. Germanskaya, O.V. Penzina, O.V. Pasko, Food Industry (2014)

14. I.D. Karomatov, A.T. Abdukhukhidov, Biology and Integrative Medicine (2018)

15. M.A. Kharchenko, Correlation analysis (Publishing and Printing Center of Voronezh State University, 2008)

16. D.V. Klyuchnikova, A.A. Kuznetsova, A.V. Krikunov, Bulletin of the South Ural State University. Series: Food and Biotechnology (2017)

17. K. Tepe, K. Agbenotowossi, G. Djeteli, S. Ouro-Djobo, K. Napo, L. Pichon, International scientific magazine: Alternative energy and ecology 2(82), 22-27 (2010) https://elibrary.ru/item.asp?id=14671143 
18. V.F. Gremenok, ECOBALTICA № 2008: Proceedings of the VI International Youth Environmental Forum (Saint-Petersburg, 2006)

19. D. Gabor, U. Colombo, A.S. King, Beyond the age of waste: a report to the Club of Rome (2016) https://www.elsevier.com/books/beyond-the-age-of-waste /gabor/978-008-027303-7

20. J. Clapp, P. Newell, Z.W. Brent, The Journal of Peasant Studies 45(1), 80-88 (2018) org/. DOI: 10.1080/03066150.2017.1381602

21. K. Govindan, International Journal of Production Economics 195, 419-431 (2018) DOI: 10.1016/j.ijpe.2017.03.003

22. X. Cai, K. Wallington, M. Shafiee-Jood, L. Marston, Advancesin Water Resources 111, 259-273 (2018) DOI: 10.1016/j.advwatres.2017.11.014.

23. A.Y. Prosekov, S.A. Ivanova, Geoforum 91, 73-77 (2018) DOI: 10.1016/j.geoforum.2018.02.030

24. O. Burdo, V. Bandura, A. Zykov, I. Zozulyak, Y. Levtrinskaya, E. Marenchenko, Eastern-European Journal of Enterprise Technologies 4.11(88), 34-42 (2017) DOI: $10.15587 / 1729-4061.2017 .108843$.

25. O.G. Burdo, V.N. Bandura, Y.O. Levtrinskaya, Surface Engineering and Applied Electrochemistry 54(2), 210-218 (2018) DOI: 10.3103/S1068375518020047

26. H.T. Sabarez, S. Keuhbauch, K. Knoerzer, IDS2018. 21st International Drying Symposium Proceedings (Universitat Politecnica de Valencia, 2018) https://www.researchgate.net/publication/330490810

27. H.T. Sabarez, Thermal Drying of Foods. Fruit Preservation (Springer, New York, 2018) https://link.springer.com/book/10.1007\%2F978-1-4939-3311-2

28. C. Kumar, M.A. Karim, Critical reviews in food science and nutrition 59.3, 379-394 (2019) https://doi. org/. DOI: 10.1080/10408398.2017.1373269 